\title{
Effects of L-thyroxine treatment on early markers of atherosclerotic disease in children with subclinical hypothyroidism
}

\author{
Manuela Cerbone', Donatella Capalbo', Malgorzata Wasniewska², Sara Alfano', \\ Giuseppina Mattace Raso ${ }^{3}$, Ugo Oliviero4, Antonio Cittadini ${ }^{4}$, Filippo De Luca ${ }^{2}$ \\ and Mariacarolina Salerno ${ }^{1}$ \\ 1Pediatric Endocrinology Unit, Department of Translational Medical Sciences, University "Federico II" \\ of Naples, Naples, Italy, ${ }^{2}$ Department of Pediatric, Gynecological, Microbiological and \\ Biomedical Sciences, University of Messina, Messina, Italy, ${ }^{3}$ Department of Pharmacy and \\ ${ }^{4}$ Internal Medicine Section, Department of Translational Medical Sciences, University "Federico II" \\ of Naples, Naples, Italy
}

\author{
Correspondence \\ should be addressed \\ to M Salerno \\ Email \\ salerno@unina.it
}

\section{Abstract}

Objective: To investigate the effect of levothyroxine (L-T4) treatment on early markers of atherosclerotic disease in children with mild idiopathic subclinical hypothyroidism (SH).

Design: Two-year, open, case-control prospective study.

Methods: A total of 39 children, aged $9.18 \pm 3.56$ years, with $\mathrm{SH}$ and 39 healthy controls were enrolled in the study. Waist-to-height ratio (WHtR), blood pressure, triglycerides, total cholesterol (total-C), HDL-C, LDL-C, non-HDL-C, triglycerides/HDL-C, atherogenic index (AI), homocysteine (Hcy), asymmetric dimethylarginine (ADMA), flow-mediated dilation (FMD) and intima-media thickness (IMT) were evaluated at baseline and after 2 years of L-T4 treatment in SH children and after 2 years of follow-up in controls.

Results: At study entry WHtR was higher in SH subjects compared with controls $(0.56 \pm 0.08$ vs $0.49 \pm 0.07, P=0.04)$ and significantly decreased after 2 years of treatment $(0.50 \pm 0.06, P<0.0001)$. Mean HDL-C levels $(50.47 \pm 11.43$ vs $61.06 \pm 13.83 \mathrm{mg} / \mathrm{dL}, P=0.002)$ were lower, while triglycerides/HDL-C (1.63 \pm 1.07 vs $1.19 \pm 0.69, P=0.05), \mathrm{Al}(3.32 \pm 0.90$ vs $2.78 \pm 0.68, P=0.005)$, and Hcy $(9.35 \pm 2.61$ vs $7.71 \pm 1.94 \mu \mathrm{mol} / \mathrm{L}, P=0.01)$ were higher in SH subjects compared with controls and improved after 2 years of treatment (HDL-C $56.26 \pm 13.76 \mathrm{mg} / \mathrm{dL}, P<0.0001$; triglycerides/HDL-C $1.23 \pm 0.78, P=0.006 ; \mathrm{Al} 2.82 \pm 0.68, P<0.0001 ;$ and $\mathrm{Hcy} 8.25 \pm 2.09 \mu \mathrm{mol} / \mathrm{L}, P=0.06)$. ADMA concentrations at baseline were higher in SH subjects compared with controls $(0.77 \pm 0.21$ vs $0.60 \pm 0.16 \mu \mathrm{mol} / \mathrm{L}, P=0.001)$ and decreased after therapy $(0.58 \pm 0.13 \mu \mathrm{mol} / \mathrm{L}, P<0.0001)$. FMD, IMT and other metabolic parameters were not different among $\mathrm{SH}$ subjects and controls at baseline and after 2 years.

Conclusions: Children with SH may have subtle pro-atherogenic abnormalities. Although L-T4 treatment exerts some beneficial effects, the long-term impact of therapy on metabolic outcomes in SH children still remains unclear.

\section{Introduction}

Subclinical hypothyroidism (SH) is a biochemical condition characterized by increased thyroid stimulating hormone (TSH) levels, with normal free T4 (FT4) concentrations (1). In adults $\mathrm{SH}$ is common with a prevalence of between 4 and 20\% and a tendency to progress to overt
() 2016 European Society of Endocrinology Printed in Great Britain hypothyroidism (1). In children SH seems to be a benign and remitting condition $(2,3,4)$ with a prevalence of less than $2 \%$ (5) and a low risk to progress to overt hypothyroidism, particularly in children with its mild and idiopathic form $(2,3,4,6)$. 
Thyroid hormone plays a key role in the working of the cardiovascular (CV) system, with direct effects on cardiac function and vascular system and on several atherosclerotic factors (7). Indeed, SH in adults has been associated with dyslipidemia $(8,9)$, insulin resistance (10), and endothelial dysfunction $(1,11,12)$. Coronary heart disease (CHD) and heart failure seem to occur more frequently in subjects with $\mathrm{SH}$, particularly for TSH levels $>10 \mathrm{mU} / \mathrm{L}(13,14,15)$ even though a recent systematic review suggests an increased stroke risk in $\mathrm{SH}$ subjects under the age of 50, with a higher risk of fatal stroke even for TSH levels between 7.0 and $9.9 \mathrm{mU} / \mathrm{L}$ (16).

Current recommendations from the American Thyroid Association suggest the start of levothyroxine (L-T4) treatment in adults with TSH levels between 4.5 and $10 \mathrm{mU} / \mathrm{L}$ in the presence of symptoms of hypothyroidism or positive thyroid antibodies or evidence of atherosclerotic CV disease (17). A recent systematic review on adults with mild to severe $\mathrm{SH}$ did not conclude for an improvement in survival or CV morbidity following L-T4 therapy; however, some beneficial effects of treatment on lipid profiles and left ventricular function were observed (18).

Health outcomes in children with untreated SH and the effects of L-T4 treatment have been less extensively evaluated; in particular, studies on the effects of mild SH on CV risk profile in children are still scanty. However, in a previous study, we documented slight alterations in visceral adiposity, lipid profile and homocysteine (Hcy) levels in a cohort of 49 prepubertal children with untreated and idiopathic SH (19). Whether this cluster of subtle pro-atherogenic abnormalities results in adverse $\mathrm{CV}$ outcomes in adulthood needs to be clarified. Understanding the clinical relevance of $\mathrm{SH}$ and L-T4 therapy on CV morbidity in SH children may help in driving the management of these subjects and in defining recommendations for their treatment. Indeed, current recommendations suggest L-T4 treatment only in children with TSH levels $>10 \mathrm{mU} / \mathrm{L}$, whereas the management of mild idiopathic $\mathrm{SH}$ is still a matter of debate $(1,3,20,21,22)$.

Only few studies have evaluated the effect of shortterm trials with L-T4 in heterogeneous populations of children with mild to severe SH $(5,20,23)$, and none of them have focused on the relationship between $\mathrm{SH}$ and metabolic aspects.

We designed this open, case-control prospective study in order to investigate the effects of 2 years of L-T4 treatment on clinical and biochemical CV risk factors in a selected cohort of children with mild idiopathic SH.

\section{Subjects and methods}

\section{Subjects and controls}

A total of 39 children (19 males), aged $9.18 \pm 3.56$ years, with untreated and idiopathic $\mathrm{SH}$ from two Italian pediatric endocrine units were enrolled in the study. These patients were a subset of the cohort of $49 \mathrm{SH}$ children previously described (19).

Inclusion criteria were the following: (a) TSH values $>4.5 \mathrm{mU} / \mathrm{L}$ and $<10 \mathrm{mU} / \mathrm{L}$ with FT4 values within the reference range persisting for at least 24 months during the period preceding the study; (b) absence of antithyroglobulin (Tg-Ab) and anti-thyroperoxidase (TPO-Ab) antibodies and normal thyroid echogenicity on ultrasound; (c) absence of palpable goiter or symptoms related to hypothyroidism from the time of $\mathrm{SH}$ identification to the beginning of the study; and (d) adequate iodine urinary excretion.

Chronic diseases, chromosomal and genetic syndromes, previous or current thyroid diseases, use of drugs that may interfere with thyroid function, previous irradiation in the neck region, detection of $\mathrm{SH}$ at neonatal screening, and familial history of genetic lipid disorders or early $\mathrm{CV}$ diseases were considered exclusion criteria.

A total of 39 healthy euthyroid children, comparable for age, sex, height, and pubertal status, were enrolled in the study as controls.

All subjects were prepubertal at baseline; during the study 9 SH subjects and 9 controls attained puberty.

Informed consent was obtained from all parents, and the study was approved by the ethics committees of the institutions.

\section{Study protocol}

At study entry all SH subjects and controls underwent clinical evaluation through measurement of height, weight, waist circumference, systolic blood pressure (SBP), and diastolic blood pressure (DBP). The degree of overall adiposity was expressed as body mass index (BMI) and calculated as weight $(\mathrm{kg}) /$ height $(\mathrm{m})^{2}$. Height and BMI were normalized by age and sex in accordance with Italian standards and expressed as standard deviation score (SDS) (24).

Waist circumference was measured, by the same operator for each center, using a flexible steel tape while the subjects were standing, after gently exhaling, as the minimal circumference measurable on the horizontal plane between the lowest portion of the rib cage and the 
iliac crest. Waist-to-height ratio (WHtR) was calculated and used as an indicator of abdominal adiposity (25).

SBP and DBP were measured at the right arm by a cuff manometer after $5 \mathrm{~min}$ of supine rest, according to the fourth report on National High Blood Pressure Education Program Working Group on High Blood Pressure in Children and Adolescents (26).

Biochemical evaluation was performed at $0800 \mathrm{~h}$ after an overnight fast, by measurement of TSH, FT4, Tg- Ab and TPO-Ab, triglycerides, total cholesterol (total-C), HDL-C, glucose, insulin, and Hcy. LDL-C was calculated using the Friedewald equation. Moreover, non-HDL-C (total-C-HDL-C), atherogenic index (AI) (total-C/HDL-C ratio) and triglycerides/HDL-C ratio were calculated as predictors of $\mathrm{CV}$ disease $(27,28,29)$.

The degree of insulin resistance was evaluated using the homeostasis model assessment (HOMA), by applying the formula: fasting serum insulin $(\mathrm{mU} / \mathrm{L}) \times$ fasting plasma glucose (mmol/L)/22.5 (30).

In addition to our previous evaluation (19), all subjects underwent evaluation of endothelial function by assessment of brachial flow-mediated dilation (FMD) and carotid intimamedia thickness (IMT) and evaluation of serum levels of asymmetric dimethylarginine (ADMA) which represents a novel biomarker of endothelial dysfunction (31).

A 2-year L-T4 treatment was started in SH subjects at an initial dose of $50 \mu \mathrm{g} /$ day and then adjusted to keep both TSH and FT4 serum levels within the reference range.
All these measurements and evaluations were re-assessed in SH subjects after 2 years of L-T4 treatment and in controls after 2 years of follow-up.

\section{Biochemical assays}

TSH and FT4 dosages were measured by electrochemiluminescence immunoassay (ECLIA) using a commercial kit (Roche Diagnostics) (normal values: TSH: $0.3-4.2 \mathrm{mU} / \mathrm{L}$, FT4: $0.8-1.7 \mathrm{pg} / \mathrm{mL}$, Tg-Ab: $0-115 \mathrm{mU} / \mathrm{L}$, TPO-Ab: $0-34 \mathrm{mU} / \mathrm{L})$. Urine iodine levels were analyzed using an automated system (Autoanalyzer 3 system, Bran+Luebbe GmbH, Nordestedt, Germany).

Serum triglycerides, total-C, and HDL-C were determined by an enzymatic in vitro test using Roche automated clinical chemistry analyzers. Hcy levels were determined by a Fluorescence Polarization Immunoassay (Abbott); inter- and intra-assay coefficients of variance were 2 and $1 \%$, respectively, and sensitivity was $0.8 \mu \mathrm{mol} / \mathrm{L}$.

ADMA was measured using ELISA (DLD, Diagnostika GMBH) (reference range $0.4-0.75 \mu \mathrm{mol} / \mathrm{L}$ ). The inter- and intra-assay coefficients of variations were 9.4 and $6.05 \%$, respectively, and sensitivity was $0.05 \mu \mathrm{mol} / \mathrm{L}$.

\section{Flow-mediated dilation and brachial artery distensibility}

FMD was obtained by a single investigator for each center. All measurements were done after 8-h fasting

Table 1 Clinical details, thyroid hormones, and biochemical parameters in children with subclinical hypothyroidism (SH) before and after 2 years of L-T4 treatment compared with controls (ANCOVA after correction for BMI). Data are expressed as mean \pm S.D.

\begin{tabular}{|c|c|c|c|c|c|c|}
\hline & \multicolumn{3}{|c|}{ Baseline } & \multicolumn{3}{|c|}{2 years after L-T4 treatment } \\
\hline & SH subjects & Controls & $P$ & SH subjects & Controls & $P$ \\
\hline Chronological age (years) & $9.18 \pm 3.56$ & $9.45 \pm 3.62$ & NS & $11.25 \pm 3.57$ & $11.42 \pm 3.59$ & NS \\
\hline TSH (mU/L) & $6.30 \pm 1.01$ & $2.92 \pm 0.68$ & 0.003 & $2.82 \pm 1.31$ & $2.53 \pm 0.67$ & NS \\
\hline FT4 (pg/mL) & $1.32 \pm 0.18$ & $1.26 \pm 0.14$ & NS & $1.37 \pm 0.22$ & $1.20 \pm 0.15$ & $<0.001$ \\
\hline Height (SDS) & $-0.65 \pm 1.32$ & $-0.47 \pm 1.24$ & NS & $-0.60 \pm 1.31$ & $-0.40 \pm 1.47$ & NS \\
\hline BMI (SDS) & $0.31 \pm 1.08$ & $-0.10 \pm 1.21$ & NS & $0.49 \pm 1.38$ & $-0.09 \pm 1.32$ & NS \\
\hline Systolic BP (mmHg) & $101.33 \pm 10.82$ & $102.36 \pm 10.79$ & NS & $102.36 \pm 10.58$ & $105.67 \pm 11.33$ & NS \\
\hline Diastolic BP (mmHg) & $64.98 \pm 9.09$ & $66.50 \pm 9.98$ & NS & $64.54 \pm 7.60$ & $63.72 \pm 8.02$ & NS \\
\hline Waist to height ratio & $0.56 \pm 0.08$ & $0.49 \pm 0.07$ & 0.04 & $0.50 \pm 0.06$ & $0.48 \pm 0.05$ & NS \\
\hline Triglycerides (mg/dL) & $74.56 \pm 39.35$ & $65.32 \pm 24.21$ & NS & $63.18 \pm 30.30$ & $58.28 \pm 19.92$ & NS \\
\hline Total cholesterol (mg/dL) & $159.72 \pm 23.36$ & $160.40 \pm 21.20$ & NS & $152.13 \pm 26.59$ & $154.40 \pm 17.07$ & NS \\
\hline HDL cholesterol (mg/dL) & $50.47 \pm 11.43$ & $61.06 \pm 13.83$ & 0.002 & $56.26 \pm 13.76$ & $57.69 \pm 11.20$ & NS \\
\hline LDL cholesterol (mg/dL) & $94.33 \pm 22.25$ & $87.19 \pm 19.43$ & NS & $83.23 \pm 25.43$ & $86.54 \pm 18.01$ & NS \\
\hline Non-HDL cholesterol (mg/dL) & $109.24 \pm 24.91$ & $100.60 \pm 20.95$ & NS & $95.87 \pm 27.30$ & $98.34 \pm 18.64$ & NS \\
\hline Triglycerides/HDL cholesterol & $1.63 \pm 1.07$ & $1.19 \pm 0.69$ & 0.05 & $1.23 \pm 0.78$ & $1.11 \pm 0.52$ & NS \\
\hline Atherogenic index & $3.32 \pm 0.90$ & $2.78 \pm 0.68$ & 0.005 & $2.82 \pm 0.68$ & $2.77 \pm 0.56$ & NS \\
\hline Homocysteine ( $\mu \mathrm{mol} / \mathrm{L})$ & $9.35 \pm 2.61$ & $7.71 \pm 1.94$ & 0.01 & $8.25 \pm 2.09$ & $8.37 \pm 1.92$ & NS \\
\hline Glucose $(\mathrm{mg} / \mathrm{dL})$ & $77.35 \pm 8.63$ & $77.30 \pm 8.62$ & NS & $78.64 \pm 8.31$ & $77.97 \pm 8.04$ & NS \\
\hline Insulin (mU/L) & $7.01 \pm 4.25$ & $5.68 \pm 3.70$ & NS & $6.92 \pm 5.38$ & $5.85 \pm 2.94$ & NS \\
\hline HOMA index & $1.38 \pm 0.90$ & $1.09 \pm 0.70$ & NS & $1.40 \pm 1.05$ & $1.15 \pm 0.60$ & NS \\
\hline ADMA $(\mu \mathrm{mol} / \mathrm{L})$ & $0.77 \pm 0.21$ & $0.60 \pm 0.16$ & 0.001 & $0.58 \pm 0.13$ & $0.61 \pm 0.15$ & NS \\
\hline
\end{tabular}



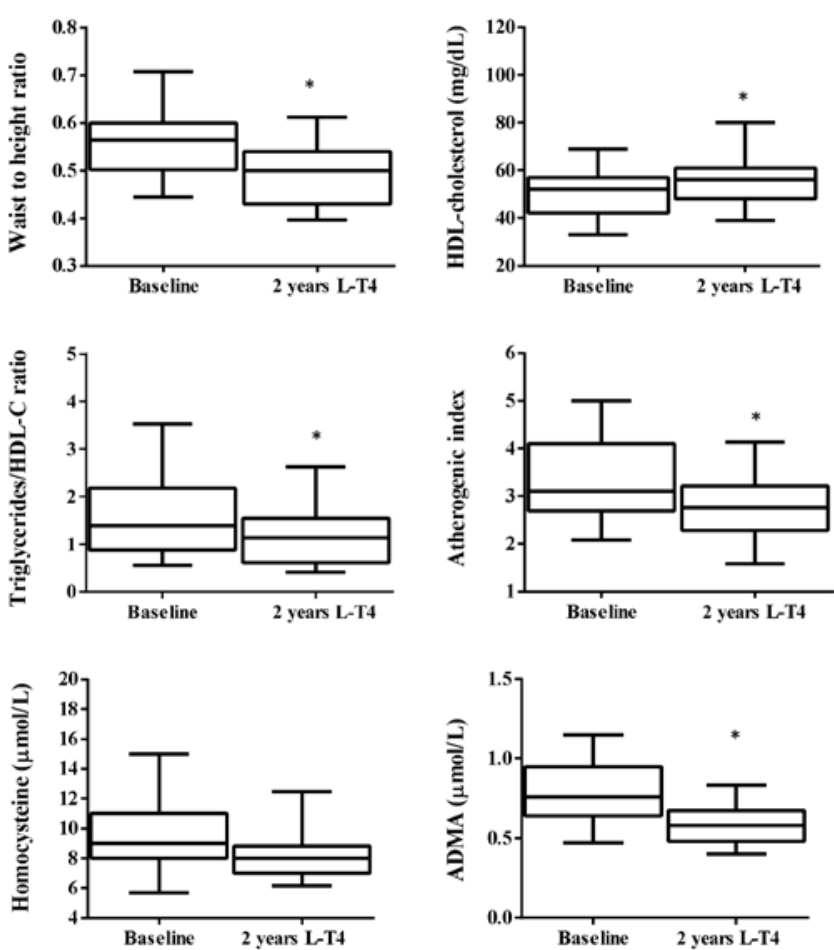

Figure 1

Waist-to-height ratio, HDL-C, triglycedrides/HDL-C ratio, atherogenic index, homocysteine, and ADMA at baseline and after 2 years of L-T4 treatment in subjects with subclinical hypothyroidism (SH). ${ }^{*} P<0.05$ comparing $\mathrm{SH}$ subjects at baseline with $\mathrm{SH}$ subjects after 2 years of therapy (see text for details on $P$ values). The boxes show medians and 25th and 75th percentiles, and the whiskers represent the 5th and the 95th percentiles.

with subjects in supine position in a quiet, temperaturecontrolled room. Brachial artery reactivity was evaluated in each subject using validated protocol (32), with a 7.5 MHz multifrequency linear array probe (Aplio XG Imaging System, Toshiba). Electrocardiographic leads were connected and a sphygmomanometer cuff was placed on the right arm. The brachial artery was imaged $2-5 \mathrm{~cm}$ proximal to the antecubital crease in a longitudinal axis, and the brachial artery diameter, from the intima-lumen interface on the near wall to the media-adventitia interface on the far wall, was measured at end-diastole cycle, on the electrocardiographic R-wave. Endothelium-dependent vasodilatation was assessed by measuring the maximum increase in brachial artery diameter during reactive hyperemia created by the inflation of the cuff $(250 \mathrm{mmHg}$ for $5 \mathrm{~min}$ ) placed on the right arm. After sudden cuff deflation, flow velocity indexes were measured in the first $15 \mathrm{~s}$; then brachial artery diameter was measured at least four times during the next 90s. FMD resulted from the formula: ((post-hyperemia diameter - baseline diameter)/ baseline diameter $) \times 100$.

The coefficient of distensibility (DC) of the brachial artery was assessed for the evaluation of arterial stiffness. The mean of three consecutive measurements was used in the analyses as recommended. Vessel diameters were measured in M-mode: the lowest end-diastolic arterial diameter $\left(D_{\mathrm{d}}\right)$ on the electrocardiographic R-wave, the highest end-systolic arterial diameter $\left(D_{\mathrm{s}}\right)$ on the electrocardiographic T-wave, and the diameter change during cardiac cycle $\left(\Delta D\right.$, defined as $\left.D_{s}-D_{\mathrm{d}}\right)$. Brachial artery pulse pressure $(\Delta P)$, defined as "SBP minus DBP," was measured by a sphygmomanometer and expressed in $\mathrm{kPa}$. Finally, DC was calculated as $\left(2 \Delta D / D_{\mathrm{d}}\right) / \Delta P$ $\left(\mathrm{kPa}^{-1} \times 10^{-3}\right)(33)$.

\section{Intima-media thickness}

Carotid ultrasound examination was performed in each subject, by experienced vascular sonographers, with a $7.5 \mathrm{MHz}$ multifrequency linear array probe. Briefly, ultrasound examination was made with the subject in a supine position, with a slight rotation of the neck. The probe was placed along the vessel axis, and carotid arteries were explored with longitudinal (anterior, lateral, and posterior) and transverse scans. Multiple long and short axis sections were employed, with special attention paid to defining the endothelial border from the origin of

Table 2 Ultrasound markers of endothelial dysfunction in children with subclinical hypothyroidism (SH) before and after L-T4 treatment compared with controls (ANCOVA after correction for BMI). Data are presented as mean \pm S.D.

\begin{tabular}{|c|c|c|c|c|c|c|}
\hline & \multicolumn{3}{|c|}{ Baseline } & \multicolumn{3}{|c|}{2 years after L-T4 treatment } \\
\hline & SH subjects & Controls & $P$ & SH subjects & Controls & $P$ \\
\hline IMT common carotid artery (mm) & $0.44 \pm 0.08$ & $0.44 \pm 0.06$ & NS & $0.46 \pm 0.07$ & $0.46 \pm 0.06$ & NS \\
\hline IMT internal carotid artery (mm) & $0.41 \pm 0.09$ & $0.41 \pm 0.07$ & NS & $0.39 \pm 0.07$ & $0.39 \pm 0.07$ & NS \\
\hline FMD $(\%)$ & $12.64 \pm 4.40$ & $13.22 \pm 3.96$ & NS & $13.90 \pm 4.92$ & $11.85 \pm 4.53$ & NS \\
\hline CD & $9.42 \pm 3.89$ & $8.80 \pm 2.74$ & NS & $8.89 \pm 3.79$ & $9.78 \pm 4.59$ & NS \\
\hline
\end{tabular}

IMT, intima-media thickness; FMD, flow mediated dilation; CD, coefficient of distensibility. 
common artery beyond the carotid artery bifurcation. On each side, IMT was measured at the bifurcation and at its proximal and distal segments, $1 \mathrm{~cm}$ before the bifurcation, on the echographic posterior wall of the common carotid artery, and $1 \mathrm{~cm}$ after the bifurcation, on the echographic posterior wall of the internal carotid artery always in the longitudinal scan.

\section{Statistical analysis}

Statistical analysis was performed using SPSS (IBM Corp. Released 2011. IBM SPSS Statistics for Windows, Version 20.0. Armonk, NY). Data are presented as mean \pm S.D. or $95 \%$ CI. Differences between groups were evaluated by linear models after adjustment for BMI (ANCOVA). Changes after L-T4 therapy in SH patients were evaluated using $T$-test for paired samples. Differences in changes from baseline over the 2 years of the study in $\mathrm{SH}$ patients compared with healthy controls were evaluated through linear model entering BMI and basal values of each parameter as covariates (ANCOVA). Pearson's correlation coefficient was used to evaluate the relationship between variables. Significance was set at $5 \%$.

\section{Results}

Clinical details, thyroid hormones and biochemical parameters in $\mathrm{SH}$ subjects and controls at baseline and after 2 years of treatment (in SH subjects) or follow-up (in control group) are reported in Table 1. As expected, at study entry TSH levels were significantly higher in $\mathrm{SH}$ subjects and became comparable to controls after 2 years of L-T4 treatment. FT4 concentrations were similar in SH children and controls at baseline and became higher than controls in SH subjects after 2 years of treatment, still remaining within the normal range.

No significant differences were observed in height SDS between patients and controls, while BMI SDS was slightly higher in SH children even though this difference did not reach statistical significance at baseline or after 2 years.

SBP and DBP were comparable between the two groups at baseline and did not change during the study.

WHtR was significantly higher in $\mathrm{SH}$ subjects and significantly decreased after 2 years of treatment $(P<0.0001)$ (Fig. 1) becoming comparable to controls (Table 1).

Serum triglycerides, total-C, LDL-C, and non-HDL-C concentrations were comparable to controls at baseline and at the end of the study (Table 1). HDL-C levels were significantly lower whereas triglycerides/HDL-C ratio, AI, $\mathrm{Hcy}$, and ADMA were significantly higher in SH subjects compared with controls at baseline. After 2 years of L-T4 therapy no more differences were observed between patients and controls in these parameters (Table 1). Indeed, a significant improvement was observed after L-T4 therapy with the exception of Hcy, which reduced without reaching statistical significance $(P<0.0001, P=0.006$, $P<0.0001, P=0.06, P<0.0001$ respectively) (Fig. 1 ).

Table 3 Changes from baseline over 2 years of L-T4 therapy in patients with SH compared with controls (ANCOVA after correction for BMI and basal values). Data are presented as mean $(95 \% \mathrm{Cl})$.

\begin{tabular}{l}
\hline \\
\hline WHtR \\
Triglycerides $(\mathrm{mg} / \mathrm{dL})$ \\
Total cholesterol $(\mathrm{mg} / \mathrm{dL})$ \\
HDL-C $(\mathrm{mg} / \mathrm{dL})$ \\
LDL-C $(\mathrm{mg} / \mathrm{dL})$ \\
Non-HDL-C $(\mathrm{mg} / \mathrm{dL})$ \\
Triglycerides/HDL-C \\
Al \\
Hcy ( $\mu \mathrm{mol} / \mathrm{L})$ \\
Glucose $(\mathrm{mg} / \mathrm{dL})$ \\
Insulin $(\mathrm{mU} / \mathrm{L})$ \\
HOMA index \\
ADMA $(\mu \mathrm{mol} / \mathrm{L})$ \\
IMT common carotid artery $(\mathrm{mm})$ \\
IMT internal carotid artery $(\mathrm{mm})$ \\
FMD $(\%)$ \\
CD
\end{tabular}

\begin{tabular}{c}
\hline SH \\
\hline$-0.05(-0.06,-0.04)$ \\
$-9.1(-16.3,-1.9)$ \\
$-7.7(-13.7,-1.8)$ \\
$2.88(-0.85,6.62)$ \\
$-9.3(-15.5,-3.1)$ \\
$-11.4(-17.6,-5.1)$ \\
$-0.26(-0.44,-0.07)$ \\
$-0.35(-0.52,-0.17)$ \\
$-0.34(-1.07,0.38)$ \\
$2.1(-0.5,4.6)$ \\
$0.47(-0.81,1.75)$ \\
$0.118(-0.134,0.370)$ \\
$-0.144(-0.186,-0.103)$ \\
$0.026(0.004,0.047)$ \\
$-0.025(-0.042,-0.008)$ \\
$1.04(-0.41,2.51)$ \\
$-0.22(-1.65,1.22)$ \\
\hline
\end{tabular}

\begin{tabular}{c}
\hline Controls \\
\hline$-0.02(-0.03,-0.01)$ \\
$-10.3(-17.7,-2.9)$ \\
$-5.3(-11.2,0.6)$ \\
$0.12(-3.61,3.86)$ \\
$-3.5(-9.7,2.7)$ \\
$-4.7(-11.0,1.5)$ \\
$-0.21(-0.41,-0.03)$ \\
$-0.15(-0.33,0.01)$ \\
$0.02(-0.66,0.72)$ \\
$0.6(-1.8,3.0)$ \\
$-0.05(-1.26,1.15)$ \\
$-0.003(-0.241,0.236)$ \\
$-0.035(-0.079,0.004)$ \\
$0.014(-0.008,0.036)$ \\
$-0.015(-0.032,0.002)$ \\
$-1.15(-2.62,0.33)$ \\
$0.73(-0.75,2.21)$
\end{tabular}

\begin{tabular}{c}
\hline $\boldsymbol{P}$ \\
\hline 0.006 \\
NS \\
NS \\
NS \\
NS \\
NS \\
NS \\
NS \\
NS \\
NS \\
NS \\
NS \\
0.001 \\
NS \\
NS \\
NS \\
NS \\
\hline
\end{tabular}

IMT, intima-media thickness; FMD, flow mediated dilation; CD, coefficient of distensibility. 
No differences were observed with regard to glucose, insulin, and HOMA levels between patients and controls throughout the course of the study (Table 1).

No significant differences were observed between SH subjects and controls in IMT, FMD and DC values at baseline and after 2 years of L-T4 treatment (Table 2).

Correlation studies revealed that changes in AI $(r=0.35, P=0.03)$, ADMA $(r=0.40, P=0.02)$ and HDL-C $(r=-0.38 P=0.02)$ significantly correlated with changes in TSH levels during therapy, while changes in WHtR were significantly related with changes in FT4 levels $(r=-0.34$, $P=0.04)$.

However, when changes from baseline between SH children and controls over the 2 years of study were compared through ANCOVA analysis (Table 3), only changes in WHtR and ADMA during therapy were deemed significant, while for other parameters the difference did not reach statistical significance.

None of our SH subjects developed adverse effects related to L-T4 treatment.

\section{Discussion}

To our knowledge, this is the first study evaluating the effect of 2 years of L-T4 treatment on early CV risk factors and vascular function in children with mild idiopathic SH. While there is general agreement in recommending L-T4 treatment for TSH levels $>10 \mathrm{mU} / \mathrm{L}$, the management of the mild form of $\mathrm{SH}$ is still debated. Although there are not sufficient data for a beneficial effect of L-T4 replacement on CV morbidity, data in SH adults suggest that L-T4 therapy improves lipid profile and left ventricular function (18).

The results of this case-control prospective study, in addition to confirming our previous findings that untreated SH in children is associated with a cluster of subtle pro-atherogenic abnormalities (19), documented an effect of L-T4 treatment on metabolic parameters.

Another novelty of our study is represented by the evaluation of precocious indices of vascular atherosclerosis in $\mathrm{SH}$ children before and after treatment. Even though no abnormalities were detected in vascular status, evaluated through FMD and IMT, ADMA concentrations, an early marker of endothelial dysfunction, were significantly increased at study entry in SH subjects and normalized after 2 years of L-T4 treatment, suggesting that mild thyroid abnormalities may be associated with early changes in pro-atherogenic profile.

ADMA is an amino acid derived from degradation of methylated proteins acting as an endogenous competitive inhibitor of endothelial nitric oxide (NO) synthase (31). NO is an anti-atherosclerotic molecule involved in a wide variety of regulatory mechanisms of the CV system, including vascular tone and structure and platelet and monocyte adhesion (31, 34). Small modifications in ADMA concentrations may affect endothelial NO production, vascular tone, and systemic vascular resistance (35), and increased ADMA levels have been associated with endothelial dysfunction and increased IMT in adults (31).

Higher ADMA levels (36) as well as impaired FMD $(11,37,38)$ and IMT (12) have been documented in adults with subclinical hypothyroidism with a beneficial effect of L-T4 therapy on endothelial function $(37,39$, $40)$ and IMT in most $(12,41)$ but not all studies $(42)$. Our finding of increased ADMA concentrations in $\mathrm{SH}$ children is in agreement with data on adults (36), although we did not observe atherosclerotic vascular wall abnormalities or endothelial dysfunction. The young age of our cohort of SH subjects could explain the absence of vascular abnormalities; indeed we could hypothesize that ADMA-mediated effects on NO availability might represent one of the mechanisms by which SH affects vascular function, and the increased levels of ADMA could represent the first step in the atherosclerotic process finally leading to structural abnormalities in adulthood.

The anthropometric evaluation did not reveal changes in height and BMI SDS after 2 years of L-T4 treatment in SH subjects, in agreement with previous data by Wasniewska et al. (20). However, after therapy we observed a significant reduction in WHtR values in SH children, suggesting that L-T4 treatment exerts a beneficial effect on visceral adiposity, as also suggested by correlation analysis which revealed a significant association between modifications in WHtR and FT4.

The relationship between lipid profile and thyroid function has been documented in childhood $(43,44,45$, 46) while so far there are no studies evaluating the effect of L-T4 therapy on lipid profile in SH children. A few randomized controlled trials in adults with $\mathrm{SH}$ found a beneficial effect of L-T4 treatment on lipid profile (40, $41,47,48)$, but this has not been confirmed by other studies (49).

Although the children in our study did not develop overt dyslipidemia, they showed at baseline a lipid profile prone to enhancement of atherosclerosis documented by subtle alterations in HDL-C, triglycerides/HDL-C, and AI. Indeed, HDL-C is inversely related to atherosclerosis, and triglycerides/HDL-C and AI are surrogate markers 
of atherosclerosis and cardiometabolic risk even in childhood $(28,29,50,51)$. Furthermore, the risk profile of $\mathrm{SH}$ children was also documented by increased Hcy levels even though the role of Hcy as CV risk factor in adults and adolescents with mild $\mathrm{SH}$ remains controversial $(9,52)$.

During the 2 years of L-T4 therapy we observed an improvement in many lipid parameters and Hcy levels in SH children. However, the analysis of differences in changes over time between SH children and controls revealed a significant treatment effect only for WHtR and ADMA. Therefore, we cannot affirm that the mild improvement in lipid profile observed in $\mathrm{SH}$ subjects is effectively due to L-T4 treatment. However, we could assume that our results are affected by both the small sample size and the high physiological variability of lipid parameters, and thus no definitive conclusions on the effects of L-T4 therapy can be drawn.

In agreement with our previous results, glucose metabolism parameters in SH children were similar to controls at baseline and did not change on L-T4 therapy. Data about the association between insulin insensitivity and $\mathrm{SH}$ are inconsistent even in adult studies (10), leading to the conclusion that insulin insensitivity does not play a role in the increased $\mathrm{CV}$ risk of these subjects.

In summary, we confirmed our previous findings of subtle pro-atherogenic abnormalities in untreated $\mathrm{SH}$ children; in addition, we documented increased ADMA levels indicating an increased risk of early endothelial dysfunction. All these abnormalities were subtle and all the parameters were still within the normal range, thus not resulting in significant alterations in vascular status, assessed through FMD and IMT. L-T4 treatment was associated with an improvement in visceral adiposity and ADMA levels; for the other outcomes evaluated we were unable to document a significant effect of treatment in comparison with controls.

Further studies on larger cohorts of patients will help clarify the impact of L-T4 therapy on early markers of atherosclerotic disease and confirm if treatment might be beneficial for children with mild SH.

\section{Declaration of interest}

The authors declare that there is no conflict of interest that could be perceived as prejudicing the impartiality of the research reported.

\section{Funding}

This research did not receive any specific grant from any funding agency in the public, commercial, or not-for-profit sectors.
Acknowledgments

We are indebted to Dario Bruzzese for his help in the statistical analysis.

\section{References}

1 Cooper DS \& Biondi B. Subclinical thyroid disease. Lancet 2012379 1142-1154. (doi:10.1016/S0140-6736(11)60276-6)

2 Wasniewska M, Salerno M, Cassio A, Corrias A, Aversa T, Zirilli G, Capalbo D, Bal M, Mussa A \& De Luca F. Prospective evaluation of the natural course of idiopathic subclinical hypothyroidism in childhood and adolescence. European Journal of Endocrinology 2009160 417-421. (doi:10.1530/EJE-08-0625)

3 Cerbone M, Bravaccio C, Capalbo D, Polizzi M, Wasniewska M, Cioffi D, Improda N, Valenzise M, Bruzzese D, De Luca F et al. Linear growth and intellectual outcome in children with longterm idiopathic subclinical hypothyroidism. European Journal of Endocrinology 2011164 591-597. (doi:10.1530/EJE-10-0979)

4 Radetti G, Maselli M, Buzi F, Corrias A, Mussa A, Cambiaso P, Salerno M, Cappa M, Baiocchi M, Gastaldi R et al. The natural history of the normal/mild elevated TSH serum levels in children and adolescents with Hashimoto's thyroiditis and isolated hyperthyrotropinaemia: a 3-year follow-up. Clinical Endocrinology 201276 394-398. (doi:10.1111/j.1365-2265.2011.04251.x)

5 Monzani A, Prodam F, Rapa A, Moia S, Agarla V, Bellone S \& Bona G. Endocrine disorders in childhood and adolescence: Natural history of subclinical hypothyroidism in children and adolescents and potential effects of replacement therapy: a review. European Journal of Endocrinology 2013168 R1-R11. (doi:10.1530/EJE-12-0656)

6 Aversa T, Valenzise M, Corrias A, Salerno M, De Luca F, Mussa A, Rezzuto M, Lombardo F \& Wasniewska M. Underlying Hashimoto's thyroiditis negatively affects the evolution of subclinical hypothyroidism in children irrespective of other concomitant risk factors. Thyroid 201525 183-187. (doi:10.1089/thy.2014.0235)

7 Cappola AR \& Ladenson PW. Hypothyroidism and atherosclerosis. Journal of Clinical Endocrinology and Metabolism 200388 2438-2444.

8 Canaris GJ, Manowitz NR, Mayor G \& Ridgway EC. The Colorado thyroid disease prevalence study. Archives of Internal Medicine 2000 160 526-534. (doi:10.1001/archinte.160.4.526)

9 Duntas LH \& Wartofsky L. Cardiovascular risk and subclinical hypothyroidism: focus on lipids and new emerging risk factors. What is the evidence? Thyroid 200717 1075-1084. (doi:10.1089/ thy.2007.0116)

10 Maratou E, Hadjidakis DJ, Kollias A, Tsegka K, Peppa M, Alevizaki M, Mitrou P, Lambadiari V, Boutati E, Nikzas D et al. Studies of insulin resistance in patients with clinical and subclinical hypothyroidism. European Journal of Endocrinology 2009160 785-790. (doi:10.1530/ EJE-08-0797)

11 Cikim AS, Oflaz H, Ozbey N, Cikim K, Umman S, Meric M, Sencer E $\&$ Molvalilar S. Evaluation of endothelial function in subclinical hypothyroidism and subclinical hyperthyroidism. Thyroid 200414 605-609. (doi:10.1089/1050725041692891)

12 Gao N, Zhang W, Zhang YZ, Yang Q \& Chen SH. Carotid intima-media thickness in patients with subclinical hypothyroidism: a meta-analysis. Atherosclerosis 2013227 18-25. (doi:10.1016/ j.atherosclerosis.2012.10.070)

13 Rodondi N, den Elzen WP, Bauer DC, Cappola AR, Razvi S, Walsh JP, Asvold BO, Iervasi G, Imaizumi M, Collet TH et al. Subclinical hypothyroidism and the risk of coronary heart disease and mortality. Journal of the American Medical Association 2010304 1365-1374. (doi:10.1001/jama.2010.1361)

14 Gencer B, Collet TH, Virgini V, Bauer DC, Gussekloo J, Cappola AR, Nanchen D, den Elzen WP, Balmer P, Luben RN et al. Subclinical thyroid dysfunction and the risk of heart failure events: an individual participant data analysis from 6 prospective cohorts. Circulation 2012 126 1040-1049. (doi:10.1161/CIRCULATIONAHA.112.096024) 
15 Razvi S, Weaver JU, Vanderpump MP \& Pearce SH. The incidence of ischemic heart disease and mortality in people with subclinical hypothyroidism: reanalysis of the Whickham Survey cohort. Journal of Clinical Endocrinology and Metabolism 201095 1734-1740. (doi:10.1210/jc.2009-1749)

16 Chaker L, Baumgartner C, den Elzen WP, Ikram MA, Blum MR, Collet TH, Bakker SJ, Dehghan A, Drechsler C, Luben RN et al. Subclinical hypothyroidism and the risk of stroke events and fatal stroke: an individual participant data analysis. Journal of Clinical Endocrinology and Metabolism 2015100 2181-2191. (doi:10.1210/ jc.2015-1438)

17 Garber JR, Cobin RH, Gharib H, Hennessey JV, Klein I, Mechanick JI, Pessah-Pollack R, Singer PA, Woeber KA \& American Association of Clinical Endocrinologists and American Thyroid Association Taskforce on Hypothyroidism in Adults. Clinical practice guidelines for hypothyroidism in adults: cosponsored by the American Association of Clinical Endocrinologists and the American Thyroid Association. Thyroid 201222 1200-1235. (doi:10.1089/thy.2012.0205)

18 Villar HC, Saconato H, Valente O \& Atallah AN. Thyroid hormone replacement for subclinical hypothyroidism. Cochrane Database of Systematic Reviews 20073 CD003419.

19 Cerbone M, Capalbo D, Wasniewska M, Mattace Raso G, Alfano S, Meli R, De Luca F \& Salerno M. Cardiovascular risk factors in children with long-standing untreated idiopathic subclinical hypothyroidism. Journal of Clinical Endocrinology and Metabolism 201499 2697-2703. (doi:10.1210/jc.2014-1761)

20 Wasniewska M, Corrias A, Aversa T, Valenzise M, Mussa A, De Martino L, Lombardo F, De Luca F \& Salerno M. Comparative evaluation of therapy with L-thyroxine versus no treatment in children with idiopathic and mild subclinical hypothyroidism. Hormone Research in Paediatrics 201277 376-381. (doi:10.1159/000339156)

21 Cerbone M, Agretti P, De Marco G, Improda N, Pignata C, Santamaria F, Tonacchera M \& Salerno M. Non-autoimmune subclinical hypothyroidism due to a mutation in TSH receptor: report on two brothers. Italian Journal of Pediatrics 2013395. (doi:10.1186/1824-7288-39-5)

22 Di Mase R, Cerbone M, Improda N, Esposito A, Capalbo D, Mainolfi C, Santamaria F, Pignata C \& Salerno M. Bone health in children with long-term idiopathic subclinical hypothyroidism. Italian Journal of Pediatrics 201238 56. (doi:10.1186/1824-7288-38-56)

23 Çatli G, Kir M, Anik A, Yilmaz N, Böber E \& Abaci A. The effect of L-thyroxine treatment on left ventricular functions in children with subclinical hypothyroidism. Archives of Disease in Childhood 2015100 130-137. (doi:10.1136/archdischild-2014-306381)

24 Cacciari E, Milani S, Balsamo A, Spada E, Bona G, Cavallo L, Cerutti F, Gargantini L, Greggio N, Tonini G et al. Italian crosssectional growth charts for height, weight and BMI (2 to $20 \mathrm{yr}$ ). Journal of Endocrinological Investigation 200629 581-593. (doi:10.1007/BF03344156)

25 Maffeis C, Banzato C, Talamini G \& Obesity Study Group of the Italian Society of Pediatric Endocrinology and Diabetology. Waistto-height ratio, a useful index to identify high metabolic risk in overweight children. Journal of Pediatrics 2008152 207-213. (doi:10.1016/j.jpeds.2007.09.021)

26 National High Blood Pressure Education Program Working Group on High Blood Pressure in Children and Adolescents. The fourth report on the diagnosis, evaluation, and treatment of high blood pressure in children and adolescents. Pediatrics 2004114 555-576.

27 van Deventer HE, Miller WG, Myers GL, Sakurabayashi I, Bachmann LM, Caudill SP, Dziekonski A, Edwards S, Kimberly MM, Korzun WJ et al. Non-HDL cholesterol shows improved accuracy for cardiovascular risk score classification compared to direct or calculated LDL cholesterol in a dyslipidemic population. Clinical Chemistry 201157 490-501. (doi:10.1373/ clinchem.2010.154773)
28 Castelli WP. Lipid, risk factors and ischaemic heart disease. Atherosclerosis 1996124 S1-S9. (doi:10.1016/0021-9150(96)05851-0)

29 Salazar MR, Carbajal HA, Espeche WG, Aizpurúa M, Leiva Sisnieguez CE, March CE, Balbín E, Stavile RN \& Reaven GM. Identifying cardiovascular disease risk and outcome: use of the plasma triglyceride/high-density lipoprotein cholesterol concentration ratio versus metabolic syndrome criteria. Journal of Internal Medicine 2013 273 595-601. (doi:10.1111/joim.2013.273.issue-6)

30 Matthews DR, Hosker JP, Rudensky AS, Naylor BA, Treacher DF $\&$ Turner RC. Homeostasis model assessment: insulin resistance and $\beta$-cell function from fasting plasma glucose and insulin concentrations in man. Diabetologia 198528 412-419. (doi:10.1007/ BF00280883)

31 Boger RH. Asymmetric dimethylarginine, an endogenous inhibitor of nitric oxide synthase, explains the "L-arginine paradox" and acts as a novel cardiovascular risk factor. Journal of Nutrition 2004134 2842S-2847S

32 Corretti MC, Anderson TJ, Benjamin EJ, Celermajer D, Charbonneau F, Creager MA, Deanfiled J, Drexler H, GerhardHerman M, Herrington D et al. International brachial artery reactivity task force, guidelines for the ultrasound assessment of endothelialdependent flow-mediated vasodilation of the brachial artery: a report of the international brachial artery reactivity task force. Journal of the American College of Cardiology 200239 257-265.

33 Nakamura M, Sugawara S, Arakawa N, Nagano M, Shizuka T, Shimoda Y, Sakai T \& Hiramori K. Reduced vascular compliance is associated with impaired endothelium-dependent dilation in the brachial artery of patients with congestive heart failure. Journal of Cardiac Failure 200410 36-42. (doi:10.1016/ S1071-9164(03)00585-2)

34 Chan JR, Böger RH, Bode-Böger SM, Tangphao O, Tsao PS, Blaschke TF $\&$ Cooke JP. Asymmetric dimethylarginine increases mononuclear cell adhesiveness in hypercholesterolemic humans. Arteriosclerosis, Thrombosis, and Vascular Biology 200020 1040-1046.

35 Sibal L, Agarwal SC, Home PD \& Boger RH. The role of asymmetric dimethylarginine (ADMA) in endothelial dysfunction and cardiovascular disease. Current Cardiology Reviews 20106 82-90. (doi:10.2174/157340310791162659)

36 Ozcan O, Cakir E, Yaman H, Akgul EO, Erturk K, Beyhan Z, Bilgi C \& Erbil MK. The effects of thyroxine replacement on the levels of serum asymmetric dimethylarginine (ADMA) and other biochemical cardiovascular risk markers in patients with subclinical hypothyroidism. Clinical Endocrinology 200563 203-206. (doi:10.1111/cen.2005.63.issue-2)

37 Taddei S, Caraccio N, Virdis A, Dardano A, Versari D, Ghiadoni L, Salvetti A, Ferrannini E \& Monzani F. Impaired endotheliumdependent vasodilatation in subclinical hypothyroidism: beneficial effect of levothyroxine therapy. Journal of Clinical Endocrinology and Metabolism 200388 3731-3737.

38 Lekakis J, Papamichael C, Alevizaki M, Piperingos G, Marafelia P, Mantzos J, Stamatelopoulos S \& Koutras DA. Flow-mediated, endothelium-dependent vasodilation is impaired in subjects with hypothyroidism, borderline hypothyroidism, and high-normal serum thyrotropin (TSH) values. Thyroid 19977 411-414. (doi:10.1089/ thy.1997.7.411)

39 Alibaz Oner F, Yurdakul S, Oner E, Kubat Uzum A \& Erguney M. Evaluation of the effect of L-thyroxin therapy on endothelial functions in patients with subclinical hypothyroidism. Endocrine 2011 40 280-284. (doi:10.1007/s12020-011-9465-2)

40 Razvi S, Ingoe L, Keeka G, Oates C, McMillan C \& Weaver JU. The beneficial effect of L-thyroxine on cardiovascular risk factors, endothelial function and quality of life in subclinical hypothyroidism: randomized, crossover trial. Journal of Clinical Endocrinology and Metabolism 200792 1715-1723.

41 Monzani F, Caraccio N, Kozàkowà M, Dardano A, Vittone F, Virdis A, Taddei S, Palombo C \& Ferrannini E. Effect of 
levothyroxine replacement on lipid profile and intima-media thickness in subclinical hypothyroidism: a double-blind, placebo-controlled study. Journal of Clinical Endocrinology and Metabolism 200489 2099-2106.

42 Jorde R, Joakimsen O, Stensland E \& Mathiesen EB. Lack of significant association between intima-media thickness in the carotid artery and serum TSH level. The Tromso Study. Thyroid 200818 21-25. (doi:10.1089/thy.2007.0165)

43 Paoli-Valeri M, Guzman M, Jimenez-Lopez V, Arias-Ferreira A, BricenoFernandez M \& Arata-Bellabarba G. Atherogenic lipid profile in children with subclinical hypothyroidism. Anales De Pediatria 2005 62 128-134. (doi:10.1157/13071309)

44 Zhang J, Jiang R, Li L, Li P, Li X, Wang Z, Li L \& Teng W. Serum thyrotropin is positively correlated with the metabolic syndrome components of obesity and dyslipidemia in Chinese adolescents. International Journal of Endocrinology 20142014289503. (doi:10.1155/2014/289503)

45 Witte T, Ittermann T, Thamm M, Riblet NB \& Völzke H. Association between serum thyroid-stimulating hormone levels and serum lipids in children and adolescents: a population-based study of German youth. Journal of Clinical Endocrinology and Metabolism $2015 \mathbf{1 0 0}$ 2090-2097. (doi:10.1210/jc.2014-4466)

46 Nader NS, Bahn RS, Johnson MD, Weaver AL, Singh R \& Kumar S. Relationships between thyroid function and lipid status or insulin resistance in a pediatric population. Thyroid 201020 1333-1339. (doi:10.1089/thy.2010.0180)
47 Meier C, Staub JJ, Roth CB, Guglielmetti M, Kunz M, Miserez AR, Drewe J, Huber P, Herzog R \& Müller B. TSH-controlled L-thyroxine therapy reduces cholesterol levels and clinical symptoms in subclinical hypothyroidism: a double blind, placebo-controlled trial (Basel Thyroid Study). Journal of Clinical Endocrinology and Metabolism 200186 4860-4866.

48 Caraccio N, Ferranini E \& Monzani F. Lipoprotein profile in subclinical hypothyroidism: response to levothyroxine replacement, a randomized placebo-controlled study. Journal of Clinical Endocrinology and Metabolism 200287 1533-1538.

49 Pearce EN. Update in lipid alterations in subclinical hypothyroidism. Journal of Clinical Endocrinology and Metabolism 201297 326-333. (doi:10.1210/jc.2011-2532)

50 Capalbo D, Mattace Raso G, Esposito A, Di Mase R, Barbieri F, Meli R, Bruzzese D \& Salerno M. Cluster of cardiometabolic risk factors in children with GH deficiency: a prospective, case-control study. Clinical Endocrinology 201480 856-862. (doi:10.1111/cen.2014.80.issue-6)

51 Di Bonito P, Moio N, Scilla C, Cavuto L, Sibilio G, Sanguigno E, Forziato C, Saitta F, Iardino MR, Di Carluccio C et al. Usefulness of the high triglyceride-to-HDL cholesterol ratio to identify cardiometabolic risk factors and preclinical signs of organ damage in outpatient children. Diabetes Care 201235 158-162. (doi:10.2337/dc11-1456)

52 Biondi B \& Cooper DS. The clinical significance of subclinical thyroid dysfunction. Endocrine Reviews 200829 76-131. (doi:10.1210/er.2006-0043)

Received 14 August 2015

Revised version received 14 March 2016

Accepted 4 April 2016 